\title{
Development and Validation of an UV-Spectrophotometric Method for the Assay of Strontium Ranelate and HPLC Stability Testing from Bulk and Pharmaceutical Dosage Form
}

Béla Kovács ${ }^{1 *}$, Réka Molnár², Előd Ernő Nagy³ ${ }^{3}$ Éva Katalin Kelemen4, Blanka Székely-Szentmiklósi ${ }^{3}$, István Székely-Szentmiklósi',5, Boglárka Kovács-Deák6, Árpád Gyéresi ${ }^{7}$

1. University of Medicine, Pharmacy, Sciences and Technology of Târgu Mureș, Romania

2. First Department of Internal Medicine, Faculty of Medicine, University of Szeged, Hungary

3. Department of Biochemistry and Environmental Chemistry, Faculty of Pharmacy, University of Medicine, Pharmacy, Sciences and Technology of Târgu

Mureș, Romania

4. Gedeon Richter, Târgu Mureș, Romania

5. Department of Pharmaceutical Industry and Management, Faculty of Pharmacy, University of Medicine, Pharmacy, Sciences and Technology of Târgu

Mures, Romania

6. Salvator Pharmacy, Târgu Mureș, Romania

7. Department of Pharmaceutical Chemistry, Faculty of Pharmacy, University of Medicine, Pharmacy, Sciences and Technology of Târgu Mureș, Romania

Objective: The present work offers a fast, reliable and easy UV spectrophotometric method for the assay of strontium ranelate from bulk samples and pharmaceutical dosage form.

Methods: The proposed method uses $0.1 \%$ VN trichloroacetic acid as dissolution medium for spectrophotometric analysis, by signal detection at $321 \mathrm{~nm}$. The method was validated according to the currently in-force international guidelines for linearity, accuracy, precision, robustness, limit of detection and quantification.

Results: The method was found to be linear in the range of 5-100 $\mu \mathrm{g} \mathrm{mL-1} \mathrm{(R2} \mathrm{>} \mathrm{0.999).} \mathrm{Method} \mathrm{accuracy} \mathrm{was} \mathrm{found} \mathrm{in-between} \mathrm{98.87-}$ $100.41 \%$, showing good linear correlation as well $(R 2=0.9997)$. The concentrations for limit of detection and limit of quantitation were found $1.13 \mu \mathrm{g} \mathrm{mL}-1$ and $3.77 \mu \mathrm{g} \mathrm{mL}-1$, resp. The proposed method showed good intra- and interday precision, with low RSD values of 0.53-1.24\% and $1.11 \%$, resp.

Conclusions: Stability studies performed by both HPLC and UV spectrophotometric methods revealed that the active substance is highly susceptible to acidic hydrolysis, oxidation and exposure to high temperature.

Keywords: strontium ranelate, UV spectrophotometry, validation, stress stability, HPLC

Received 25 April 2019 / Accepted 11 June 2019

\section{Introduction}

Strontium ranelate (SrR, Protelos, Osseor), chemically is the di-strontium salt of 2-(2-carboxy-4-cyano-5-[N,Ndi(carboxymethyl)amino] thiophene-3-yl) acetic acid (ranelic acid) (Fig. 1), is used in the treatment of postmenopausal osteoporosis, having a positive risk/benefit ratio, and represents a viable alternative when medication with other anti-osteoporotic agents is futile [1]. The active substance is freely soluble in aqueous media at $\mathrm{pH}<2$, presenting a decreasing solubility by reaching the neutral domain. It is practically insoluble in organic solvents [2].

Literature data revealed that only a few UV spectrophotometric methods have been reported for strontium ranelate so far [3-6]. Further analytical methods imply RPHPLC determination [7-10] and capillary zone electrophoresis [11] for the determination of the active substance.

According to the guidelines Q1A (R2) and Q1B published by the International Conference on Harmonization, the forced degradation studies of the active substances are helpful for the identification of the possible degradation products and also may be applied for the evaluation of the intrinsic stability of the molecule. The stress stability

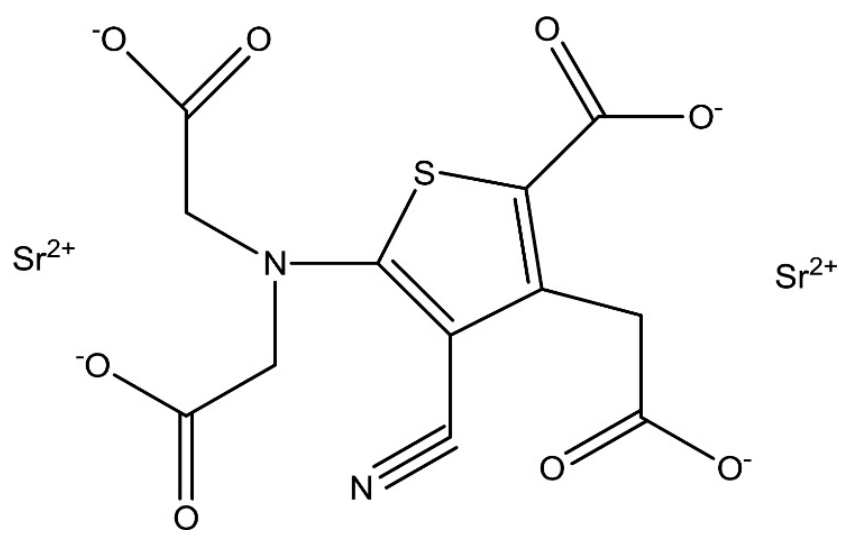

Fig. 1. Chemical structure of strontium ranelate 
testing of an active substance according to the mentioned directives should include the effect of temperature, humidity, oxidative conditions, photolysis and hydrolysis across a wide $\mathrm{pH}$ range. Also, it is specified that photolysis should be performed under a light source which provides an illumination greater than 1.2 million lux, and an energy in the near UV of not less than $200 \mathrm{Wh} / \mathrm{m}^{2}[12,13]$.

Taking into consideration that the already available UV spectrophotometric methods for the assay of strontium ranelate use a multicomponent solvent system, having a prolonged sample preparation time, our main objective was to develop and validate a high throughput, cost-effective and accessible method for the assay of strontium ranelate from both bulk samples and pharmaceutical dosage form. Moreover, we aimed to test the stability of the active substance in accordance with the currently in-force international guidelines with two different analytical methods using an already available HPLC method and the currently presented UV spectrophotometric method.

\section{Material and methods}

\section{Reagents}

Strontium ranelate $(\mathrm{SrR})$ standard was purchased from Sigma Aldrich (St. Louis, USA) and bulk active pharmaceutical ingredient (strontium ranelate octahydrate) was obtained from Dishman Pharmaceuticals and Chemicals (Ahmedabad, India). Trichloroacetic acid (TCAA) and trifluoroacetic acid (TFA) was used from Merck (Darmstadt, Germany). Water, purified was obtained by means of a Milli-Q water purification system (Millipore, Merck, Germany). Osseor 2-g granules for oral suspension (Lés Laboratoires, Serviér, France) was purchased from local pharmacies. Selectivity studies were performed using mannitol (Pearlitol 300DC, Ph. Eur., Roquette Pharma, France), maltodextrin (Lycatab DSH, Ph. Eur., Roquette Pharma, France) and aspartame (Ph. Eur., Sigma Aldrich, USA), excipients of the original product.

\section{Preparation of standard solution}

Standard solution was prepared by dissolving $4 \mathrm{mg} \mathrm{SrR}$ in TCAA $0.1 \% \mathrm{~V} / \mathrm{V}$ solution in a $100 \mathrm{~mL}$ volumetric flask, and completed to the mark with the same solution, obtaining a final concentration of $40 \mu \mathrm{g} \mathrm{mL}-1$.

\section{Apparatus and spectrophotometric method}

UV spectrophotometric determination was performed using a Shimadzu 1800 UV-VIS (Shimadzu Co., Kyoto, Japan) spectrophotometer, special optical glass (OS type, Hellma Analytics, Müllheim, Germany) cuvettes with an optical path of $10 \mathrm{~mm}$. For the evaluation of the optimal determination wavelength a scanning run $(200-400 \mathrm{~nm})$ was carried out and TCAA $0.1 \% \mathrm{~V} / \mathrm{V}$ was used as a blank solution. For robustness studies a Labomed UVD-3200 (Labomed Inc., Los Angeles, USA) spectrophotometer was used for comparison. Furthermore, method robustness was tested for the type of the cuvettes used for routine analysis, as the specification of OS type cuvettes indicates that it is useable in the range of $320-2500 \mathrm{~nm}$. Absorbance of SrR stock solution was evaluated for both OS type and QS (Suprasil ${ }^{\circ}$ quartz glass, Hellma Analytics, Müllheim, Germany) type cuvettes, for which the recommended working interval is greater, lying between $200-2500 \mathrm{~nm}$.

\section{Method validation}

Linearity. - Method linearity was assessed in the range of $5-100 \mu \mathrm{g} \mathrm{mL}^{-1}$ in seven points $(5,10,20,40,60,80,100$ $\left.\mu \mathrm{g} \mathrm{mL}^{-1}\right)$, repeated five times for each concentration. Solutions were prepared by dilution with TCAA $0.1 \% \mathrm{~V} / \mathrm{V}$ from a stock solution of $100 \mu \mathrm{g} \mathrm{mL}-1$.

Selectivity - The selectivity of the method was investigated considering the quantitative and qualitative composition of Osseor $2 \mathrm{~g}$ granules for oral suspension. Placebo formulation was prepared using $4.0 \mathrm{~g}$ mannitol, 0.4 $\mathrm{g}$ maltodextrin, and $0.02 \mathrm{~g}$ aspartame per dose. Selectivity was evaluated by comparing the absorbance spectrum of individually prepared samples of the excipients, placebo mixture, and placebo spiked with SrR. All samples were prepared under the same conditions using TCAA $0.1 \%$ $\mathrm{V} / \mathrm{V}$ as dissolution medium.

Accuracy (recovery) - The accuracy of the method was tested using placebo mixture samples spiked with SrR, at five concentration levels $(50 \%, 75 \%, 100 \%, 125 \%$, and $150 \%)$ of the working concentration, repeated three times for each concentration.

Robustness - Method robustness was verified for individual changes in detection wavelength $(321 \mathrm{~nm} \pm 2 \mathrm{~nm})$, temperature $\left(4^{\circ} \mathrm{C}\right.$ vs. $\left.25^{\circ} \mathrm{C}\right)$, instrumentation (Shimadzu 1800 vs. Labomed UVD-3200), $\mathrm{pH}(2.0 \pm 0.2)$ and cuvette type (OS vs. QS).

Precision - The precision of the method was evaluated for both intraday- (repeatability) and intermediate precision. Six individual samples were prepared on the same day and on two different days by two analysts. Samples were prepared from Osseor $2 \mathrm{~g}$ granules corresponding to 3.12 mg SrR anhydrous.

Limit of detection (LOD) and limit of quantification (LOQ) - LOD and LOQ were calculated from the calibration plot as $3.3 \sigma / S$ and $10 \sigma / S$, resp., where $\sigma$ is the standard error of the intercept and $S$ represents the slope of the calibration plot.

\section{Statistical analysis}

Statistical analyses were carried out using Minitab 17.0 (Coventry, UK) and Statistica 8.0 (Tulsa, USA) software for the validation of the UV spectrophotometric method.

Method linearity and the normal distribution of the residuals was tested using the Shapiro-Wilk's test (confidence interval of 95\%). Statistical significance was considered if both of the following criteria are met: the $\mathrm{W}$ value for $\mathrm{SrR}$ was greater than the critical tabulated value and $p>0.05$. ANOVA F-test and its test for lack of fit (confidence limit 
of 95\%) was used for the assessment of the significance of the calibration curve.

Student's t-test was used for statistically evaluating the intraday and intermediate precision results (confidence level of $95 \%$ ).

\section{Stress stability testing}

Stability testing was performed for acidic - (with $0.1 \mathrm{M}$ $\mathrm{HCl}$ ) and alkali hydrolysis (with $0.1 \mathrm{M} \mathrm{NaOH}$ ), oxidative stress $\left(3 \% \mathrm{H}_{2} \mathrm{O}_{2}\right)$, thermal degradation $\left(60^{\circ} \mathrm{C}\right.$ and $120^{\circ} \mathrm{C}$ for $2 \mathrm{~h}$ ) and photolysis (under a $125 \mathrm{~W} \mathrm{UV} \mathrm{lamp} \mathrm{for} 2 \mathrm{~h}$ ). For the acidic-, and alkali hydrolysis, oxidative stress conditions three samples, with two replicates were prepared individually for time points of 1,2 and 7 days. Thermal degradation and photolysis studies were also performed from two replicate samples under the specified conditions.

Sample preparation for HPLC determination - for stability testing $4 \mathrm{mg}$ of $\mathrm{SrR}$ and $6.24 \mathrm{mg}$ of Osseor were weighed in $50 \mathrm{~mL}$ volumetric flasks. For acidic and alkali hydrolysis and oxidative stress conditions $2 \mathrm{~mL}$ of $0.1 \mathrm{M}$ $\mathrm{HCl}, 0.1 \mathrm{M} \mathrm{NaOH}$ and $3 \% \mathrm{H}_{2} \mathrm{O}_{2}$ were added, resp. The samples were held in closed dark chambers until sampling. Before analysis, the samples were completed with TFA $0.1 \% \mathrm{~V} / \mathrm{V}$, stirred on an ultrasound bath for 2 minutes and filtered through a $0.45-\mu \mathrm{m}$ Whatman nylon filter (General Electric Healthcare, UK) in brown HPLC vials. The first $2 \mathrm{~mL}$ of the filtered solution were discarded. For thermal degradation studies and photolysis the volumetric flasks were completed with TFA $0.1 \% \mathrm{~V} / \mathrm{V}$ after weighing, stirred on an ultrasound bath for 2 minutes and filtered through a $0.45-\mu \mathrm{m}$ Whatman nylon filter in brown HPLC vials, prior to analysis.

Sample analysis was performed according to the method described by Kovács et al. [9].

Sample preparation for UV spectrophotometric determination - for stability testing $4 \mathrm{mg}$ of $\mathrm{SrR}$ and $6.24 \mathrm{mg}$ of Osseor were weighed in $50 \mathrm{~mL}$ volumetric flasks. For acidic and alkali hydrolysis and oxidative stress conditions $2 \mathrm{~mL}$ of $0.1 \mathrm{M} \mathrm{HCl}, 0.1 \mathrm{M} \mathrm{NaOH}$ and $3 \% \mathrm{H}_{2} \mathrm{O}_{2}$ were added, resp. The samples were held in closed dark chambers until sampling. Before analysis, the samples were completed with TCAA $0.1 \% \mathrm{~V} / \mathrm{V}$. For thermal degradation studies and photolysis the volumetric flasks were completed with TCAA $0.1 \% \mathrm{~V} / \mathrm{V}$ after weighing.

\section{Results and discussion}

Absorption spectrum and selectivity. - The absorption spectrum of the stock solution revealed that strontium ranelate has an absorbance maximum at $\lambda=321 \mathrm{~nm}$. Selectivity studies elucidated that there is no interference between strontium ranelate and the selected excipients at $\lambda=321$ $\mathrm{nm}$. Furthermore, no change in absorbance maximum was observed between the two types of cuvettes tested (Fig. 2).

Linearity. - The method was found to be linear in the range of $5-100 \mu \mathrm{g} \mathrm{mL}^{-1}\left(\mathrm{R}^{2}=0.9999\right)$. The normal distribution of residuals was evaluated by the Shapiro-Wilk's test, indicating that the residuals follow a normal distribution, as the $\mathrm{W}_{\mathrm{SrR}}$ is greater than the critical tabulated value, $\mathrm{W}_{\mathrm{c}}$, and $\mathrm{p}>0.05$.

Accuracy (recovery). - The recovery of placebo spiked samples were found between $98.87-100.41 \%$ for the tested range of $50-150 \%$ of the working concentration, fulfilling the requirements of international standard to be inbetween $95-105 \%$. The mean recovery was found to be $99.24 \%$. The linearity of the tested samples showed a good correlation with $\mathrm{R}^{2}=0.9997$.

Robustness. - The method was found to be robust for all tested changes, the obtained concentrations lying between $98.23-102.16 \%$.

Method precision. - The precision of the method returned low RSD\% values for both the intraday (0.53$1.24 \%)$ and intermediate precision (1.11\%).

Limit of quantification and limit of detection. - Based on the regression analysis LOD and LOQ values were calculated, resulting in $1.13 \mu \mathrm{g} \mathrm{mL}^{-1}$ and $3.77 \mu \mathrm{g} \mathrm{mL}^{-1}$, resp.

The presented method offers a greater linearity interval in comparison to the already available UV-spectrophotometric methods for the assay of strontium ranelate, where depending on the dissolution medium and method peculiarities linearity ranges of $2-20 \mu \mathrm{g} \mathrm{mL}^{-1}$ [3], $4-28 \mu \mathrm{g} \mathrm{mL}^{-1}$ [4], 5-55 $\mu \mathrm{g} \mathrm{mL}^{-1}$ [5] and 5-50 $\mu \mathrm{g} \mathrm{mL}^{-1}$ [6] are reported. Although the current method only approximates the lower limits of the disclosed methods $\left(5 \mu \mathrm{g} \mathrm{mL}^{-1}\right.$ vs. $2-4 \mu \mathrm{g}$ $\mathrm{mL}^{-1}$ ), the upper limit is substantially superior when compared to literature data $\left(100 \mu \mathrm{g} \mathrm{mL}^{-1}\right.$ vs. $\left.50-55 \mu \mathrm{g} \mathrm{mL} \mathrm{L}^{-1}\right)$. Method accuracy shows similar recovery intervals to the referred methods. Our method is more bounded regarding the LOD and LOQ values $\left(1.13 \mu \mathrm{g} \mathrm{mL}^{-1}\right.$ and $3.77 \mu \mathrm{g}$ $\mathrm{mL}^{-1}$, resp.) when compared e.g. to the values presented

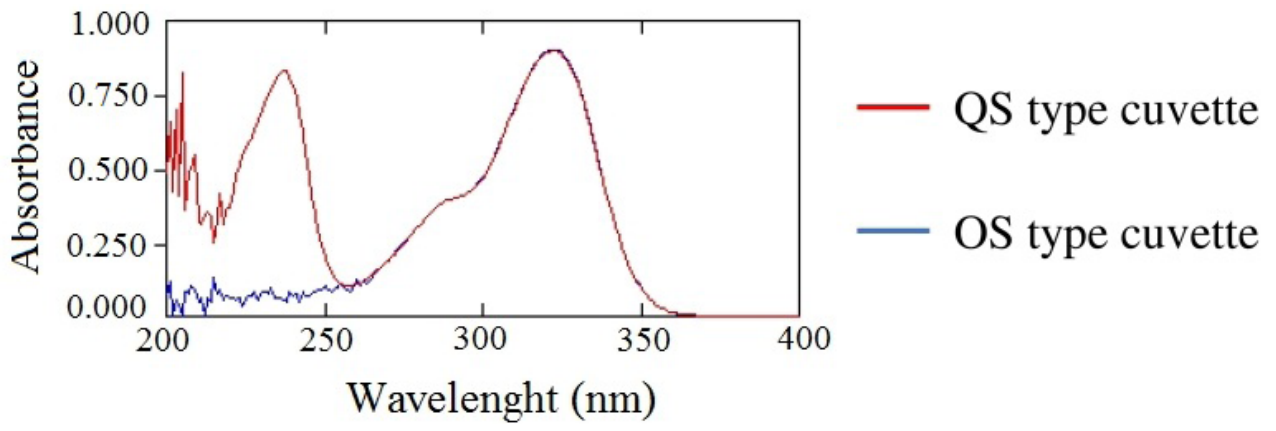

Fig. 2. Absorbance spectrum of strontium ranelate using QS (special quartz) and OS (special optic) type cuvettes 
by Swami et al. [4] of $0.013 \mu \mathrm{g} \mathrm{mL}-1$ and $0.043 \mu \mathrm{g} \mathrm{mL}-1$ for LOD and LOQ, resp. Finally, as the previous studies lack the robustness testing of the method, the newly developed technique assessed the impact of general variables (detection wavelength, instrumentation, cuvette type) on method performance and tested them during the validation procedure (Table I).

Stress stability testing. - The active substance proved to be highly susceptible to acidic hydrolysis, oxidative stress and thermal degradation, especially at high temperatures. Alkali conditions, UV light or lower thermal impact has only a negligible effect on the stability of SrR. The results are in concordance with the finding presented by Swami et al. [7], as the active substance subjected to acidic hydrolysis and oxidative stress ( $1 \mathrm{M} \mathrm{HCl}$ and $3 \% \mathrm{H}_{2} \mathrm{O}_{2}$ for $1 / 2$ hour) presents high degradation ( $77.15 \%$ and $80.89 \%$, resp.), whilst under thermal impact $\left(60^{\circ} \mathrm{C}\right.$ for $1 / 2$ hour), alkali hydrolysis ( $1 \mathrm{M} \mathrm{NaOH}$ for $1 / 2$ hour) and UV irradiation (24 hours) only slight decomposition of SrR was observed (94.77\%, $97.59 \%$ and $98.19 \%$, resp.).

The stability testing results are similar to the ones obtained in our previous HPLC studies [9]. The degradation profile presents the same level, to a certain extent, regarding hydrolysis, oxidative and photolytic studies for both HPLC and UV-spectrophotometric determinations (Table II and III).

\section{Conclusions}

The presented UV spectrophotometric method proved to be adequate for the routine analysis of strontium ranelate

Table I. Analytical merits of the developed UV-spectrophotometric method

\begin{tabular}{|c|c|c|}
\hline Parameter & Results & Statistical results \\
\hline Linearity ( $\mu \mathrm{g} \mathrm{mL} \mathrm{L}^{-1}$ ) & $\begin{array}{c}5-100 \\
(y=0.0242 x+0.0116)\end{array}$ & $\begin{aligned} R^{2} & =0.99991(n=7) \\
W_{S r R} & =0.911(p=0.40)^{a} \\
C p k & =2.43^{d}\end{aligned}$ \\
\hline Accuracy (\%) & $98.87-100.41$ & $R^{2}=0.9997(n=5)$ \\
\hline Intraday precision (RSD, \%), $\mathrm{n}=6$ & $0.53-1.24$ & 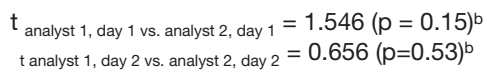 \\
\hline Inter-day precision (RSD, \%), $n=24$ & 1.11 & $\begin{array}{c}\mathrm{t}_{\text {analyst } 1 \text {, day } 1 \text { vs. analyst } 2 \text {, day } 2}=0.580(\mathrm{p}=0.57)^{\mathrm{b}} \\
\mathrm{t}_{\text {analyst } 1 \text {, day } 1 \text { vs. analyst } 1 \text {, day } 2}=0.298(\mathrm{p}=0.77)^{\mathrm{b}} \\
\mathrm{t}_{\text {analyst } 1 \text { vs. analyst } 2}=1.614(\mathrm{p}=0.12)^{\mathrm{c}}\end{array}$ \\
\hline Instrument precision (RSD, \%) & 0.33 & - \\
\hline $\operatorname{LOD}\left(\mu \mathrm{g} \mathrm{mL}^{-1}\right)$ & 1.13 & - \\
\hline $\mathrm{LOQ}(\mu \mathrm{g} \mathrm{mL}-1)$ & 3.77 & - \\
\hline
\end{tabular}

${ }^{a} W_{c}=0.850$, critical value of Shapiro-Wilk's test; ${ }^{b}$ Critical value of $t=2.228, d f=10 ;{ }^{c}$ Critical value of $t=2.074, d f=22 ;{ }^{d} C_{p k}>1.33$ (limit of acceptance for process capability)

Table II. Stress stability test results of strontium ranelate bulk samples and Osseor® by RP-HPLC

\begin{tabular}{|c|c|c|c|c|c|c|c|}
\hline \multicolumn{8}{|c|}{ Strontium ranelate bulk sample, $\%$ of degradation by HPLC } \\
\hline & \multirow{2}{*}{ Stock solution } & \multirow{2}{*}{$\mathrm{NaOH} 0.1 \mathrm{M}$} & \multirow{2}{*}{$\mathrm{HCl} 0.1 \mathrm{M}$} & \multirow{2}{*}{$\mathrm{H}_{2} \mathrm{O}_{2} 3 \%$} & \multicolumn{2}{|c|}{ Thermal degradation } & \multirow{2}{*}{$\begin{array}{l}\text { UV light } \\
\text { exposure }\end{array}$} \\
\hline & & & & & $60^{\circ} \mathrm{C} / 2 \mathrm{~h}$ & $105^{\circ} \mathrm{C} / 24 \mathrm{~h}$ & \\
\hline Day 1 & 3.55 & Nil & 8.11 & 8.20 & \multirow{3}{*}{17.19} & \multirow{3}{*}{100.00} & \multirow{3}{*}{2.70} \\
\hline Day 2 & 9.32 & Nil & 10.54 & 27.96 & & & \\
\hline Day 7 & 31.97 & 0.96 & 37.75 & 43.02 & & & \\
\hline \multicolumn{8}{|c|}{ Osseor ${ }^{\circledR}$ samples, $\%$ of degradation by HPLC } \\
\hline & \multirow{2}{*}{ Stock solution } & \multirow{2}{*}{$\mathrm{NaOH} 0.1 \mathrm{M}$} & \multirow{2}{*}{$\mathrm{HCl} 0.1 \mathrm{M}$} & \multirow{2}{*}{$\mathrm{H}_{2} \mathrm{O}_{2} 3 \%$} & \multicolumn{2}{|c|}{ Thermal degradation } & \multirow{2}{*}{$\begin{array}{l}\text { UV light } \\
\text { exposure }\end{array}$} \\
\hline & & & & & $60^{\circ} \mathrm{C} / 2 \mathrm{~h}$ & $105^{\circ} \mathrm{C} / 24 \mathrm{~h}$ & \\
\hline Day 1 & 3.65 & Nil & 6.80 & 8.97 & & & \\
\hline Day 2 & 6.76 & $\mathrm{Nil}$ & 9.86 & 32.13 & 4.38 & 100.00 & 0.26 \\
\hline Day 7 & 23.61 & 0.59 & 35.65 & 57.84 & & & \\
\hline
\end{tabular}

Table III. Stress stability test results of strontium ranelate bulk samples and Osseor® by UV-spectrophotometry

\begin{tabular}{|c|c|c|c|c|c|c|c|}
\hline \multicolumn{8}{|c|}{ Strontium ranelate bulk sample, \% of degradation by UV spectrophotometry } \\
\hline & \multirow{2}{*}{ Stock solution } & \multirow{2}{*}{$\mathrm{NaOH} 0.1 \mathrm{M}$} & \multirow{2}{*}{$\mathrm{HCl} 0.1 \mathrm{M}$} & \multirow{2}{*}{$\mathrm{H}_{2} \mathrm{O}_{2} 3 \%$} & \multicolumn{2}{|c|}{ Thermal degradation } & \multirow{2}{*}{ UV light exposure } \\
\hline & & & & & $60^{\circ} \mathrm{C} / 2 \mathrm{~h}$ & $105^{\circ} \mathrm{C} / 24 \mathrm{~h}$ & \\
\hline Day 1 & 2.26 & Nil & 8.24 & 3.74 & \multirow{3}{*}{9.90} & \multirow{3}{*}{87.87} & \multirow{3}{*}{3.20} \\
\hline Day 2 & 7.69 & Nil & 12.91 & 9.59 & & & \\
\hline Day 7 & 25.73 & 0.95 & 26.60 & 61.25 & & & \\
\hline \multicolumn{8}{|c|}{ Osseor $®$ samples, \% of degradation by UV spectrophotometry } \\
\hline & \multirow[b]{2}{*}{ Stock solution } & \multirow[b]{2}{*}{$\mathrm{NaOH} 0.1 \mathrm{M}$} & \multirow[b]{2}{*}{$\mathrm{HCl} 0.1 \mathrm{M}$} & \multirow[b]{2}{*}{$\mathrm{H}_{2} \mathrm{O}_{2} 3 \%$} & \multicolumn{2}{|c|}{ Thermal degradation } & \multirow[b]{2}{*}{ UV light exposure } \\
\hline & & & & & $60^{\circ} \mathrm{C} / 2 \mathrm{~h}$ & $105^{\circ} \mathrm{C} / 24 \mathrm{~h}$ & \\
\hline Day 1 & 2.53 & Nil & 2.48 & 3.27 & & & \\
\hline Day 2 & 7.70 & Nil & 11.11 & 6.91 & 14.24 & 97.98 & 2.86 \\
\hline Day 7 & 17.40 & 0.72 & 26.55 & 50.34 & & & \\
\hline
\end{tabular}


from both bulk samples and pharmaceutical dosage forms. The method offers a high throughput, low cost sample measurement, using conventional apparatus and single component solvent system (TCAA $0.1 \%$ ). The validated method according to the currently in-force international guidelines presents an appropriate linearity in the range of $5-100 \mu \mathrm{g} \mathrm{mL}^{-1}$ and a mean recovery of $99.24 \%$. Moreover, the method proved to be applicable regardless of the type of cuvettes, thus might ease the analytical transfer between control laboratories. Furthermore, taking into consideration the precision of the method validated from Osseor $2 \mathrm{~g}$ granules for oral suspension, this determination might represent an alternative to the currently available analytical methods. Both the HPLC and UV spectrophotometric methods proved to be adequate for the determination of the degradation profile of strontium ranelate, the method having its limitations in the quantification of the formed impurities. The stability studies of the active pharmaceutical ingredient from both bulk samples and pharmaceutical dosage form revealed that it is highly susceptible to acidic hydrolysis, oxidative stress and heat being slightly influenced in alkali media and UV light exposure.

\section{Authors' contribution}

Béla Kovács (Conceptualization; Validation; Writing original draft)

Réka Molnár (Formal analysis; Validation)

Előd Ernő Nagy (Supervision; Writing - review \& editing) Éva Katalin Kelemen (Funding acquisition; Writing - review \& editing)

Blanka Székely-Szentmiklósi (Writing - review \& editing) István Székely-Szentmiklósi (Project administration; Writing - original draft)

Boglárka Kovács-Deák (Formal analysis; Writing - original draft)

Árpád Gyéresi (Writing - review \& editing)

\section{Acknowledgements}

B.K. is awarded with a Collegium Talentum Scholarship and thanks for the support.

\section{Conflict of interest}

None to declare.

\section{References}

1. Reginster JY, Brandi ML, Cannata-Andía $J$ et al - The position of strontium ranelate in today's management of osteoporosis. Osteoporos Int. 2015;26:1667-71

2. EMEA, European Medicines Agency, Osseor, Scientific Discussion, London 2005; http://www.ema.europa.eu/docs/en GB/document library/EPAR_-_ Scientific_Discussion/human/000561/WC500051099. pdf; last access date: May 10, 2018

3. Mythili K, Gayatri S, Kumar EM, et al - Development and validation of UV spectrophotometric method for the estimation of strontium ranelate in sachet formulation. Research Journal of Pharmacy and Technology. 2011;4:1468-70

4. Swami AS, Pishawikar AS, More HN - UV-spectrophotometric method development and validation for estimation of strontium ranelate in bulk. International Journal of Pharma and Bio Sciences. 2012;3: 171-76

5. Rizk M, El-Alamin MMA, Moawad MI - A simple kinetic spectrophotometric method for determination of strontium ranelate in bulk and pharmaceutical dosage form. Indo American Journal of Pharmaceutical Research. 2015;5:2503-12

6. Chavan DS, Pishawikar SA, More HN et al - Validated Spectrophotometric Method Development for Strontium Ranelate from Newly Developed Floating Tablet Formulation. International Journal of Science and Research. 2018;7:634-37

7. Swami AS, Pishawikar AS, More HN - Forced degradation study of strontium ranelate (anti-osteoporotic drug). International Journal of Pharmaceutical Sciences Review and Research; 2012, 12(2): 22-6

8. Reddy BRCS, Rao NVB - A validated stability indicating RP-HPLC method for the determination of strontium ranelate a dual acting bone agent in bulk and sachet dosage form. Rasayan Journal of Chemistry. 2014;7:20-7

9. Kovács B, Kántor LK, Croitoru MD et al - Reversed phase HPLC for strontium ranelate: Method development and validation applying experimental design. Acta Pharm. 2018;68:171-83

10. Mythili K, Gayatri S, Teja KR, et al - Development and validation of RP-HPLC method for the estimation of strontium ranelate in sachet. International Journal of Pharma and Bio Sciences. 2011;2:258-63

11. de Carvalho RC, Netto ADP, de Carvalho Marques FF - Simultaneous determination of strontium ranelate and aspartame in pharmaceutical formulation for the treatment of postmenopausal osteoporosis by capillary zone electrophoresis. Microchemical Journal. 2014;117:214-19

12. ICH International Conference on Harmonization, Harmonized Tripartite Guideline - Stability testing of New Drug Products Q1A (R2), Step 4, 2003; https://www.ich.org/fileadmin/Public_Web_Site/ICH_Products/ Guidelines/Quality/Q1A_R2/Step4/Q1A_R2_Guideline.pdf; accessed on: 30th of August 2018

13. ICH Harmonized Tripartite Guideline - Stability testing: Photostability of New Drug Substances and Products Q1B, Step 4, 1996é https://www. ich.org/fileadmin/Public_Web_Site/ICH_Products/Guidelines/Quality/ Q1B/Step4/Q1B_Guideline.pdf; accessed on: 30th of August 2018 